\title{
The Current Indications and Options for Aortic Valve Surgery
}

\section{Introduction}

This review article provides an overview of various aortic valve pathologies and when intervention is indicated with each one. The management options and their controversies are then reviewed, including new technologies, specifically the transcatheter aortic valves and sutureless aortic valves. Aortic root or ascending aorta pathology is out of the scope of this chapter, which focuses on pure aortic valvular disease. Classes of recommendation are often referenced and the definitions are summarized in Table 1.

\section{Indications}

\section{Aortic stenosis}

Aortic stenosis is the most common indication for aortic valve surgery. The incidence increases with age, but it is not a part of normal aging, affecting only $2 \%$ of patients over 65 years old [1]. Once mild obstruction is occurred, the valve progresses to severe stenosis in 5-10 years. Severe outflow obstruction is initially compensated by left ventricular hypertrophy, characterized by increased myocyte size. Once this compensation is no longer enough, symptoms appear. Symptoms portend a very poor prognosis with a $50 \%$ mortality in 2 years if untreated. The mean survival is 4.5 years after onset of angina, 2.6 years after the onset of syncope and less than a year after the onset of left heart failure [2]. However, in the absence of symptoms, survival remains quite good with the risk of sudden death less than 1 $\%$ per year [3]. Therefore, the indication for surgical intervention is usually the onset of symptoms.

Other Class I indications for surgery according to the latest American Heart Association (AHA) guidelines (2014) include severe aortic stenosis in patients undergoing other heart surgery and asymptomatic severe aortic stenosis with evidence of left ventricular dysfunction $[4,5]$. The end stage of the disease results in eccentric remodeling, ventricular dilatation and heart failure. A certain degree of reverse remodeling is possible after aortic valve replacement, prompting surgical intervention with left ventricular dysfunction even in the absence of symptoms. The European Society of Cardiology (ESC) guidelines (2012) also include the provocation of symptoms during exercise testing as a Class I indication [6]. Additionally, both societies consider replacement of the aortic valve in patients with moderate aortic stenosis who are undergoing other heart surgery as a Class IIa recommendation. A fall in blood pressure during exercise testing, transcatheter aortic valve implantation as recommended by a 'heart team', and very severe aortic stenosis are other Class IIa recommendations of ESC.

Table 1: Classes of recommendation.

\begin{tabular}{|l|l|}
\hline Class I & $\begin{array}{l}\text { Evidence or general agreement that the treatment or procedure } \\
\text { should be performed. }\end{array}$ \\
\hline Class Ila & $\begin{array}{l}\text { Weight of the evidence or opinion is that it is reasonable to } \\
\text { perform the treatment or procedure. }\end{array}$ \\
\hline Class IIb & $\begin{array}{l}\text { Evidence or opinion is conflicting, but one can consider } \\
\text { performing the treatment or procedure. }\end{array}$ \\
\hline Class III & $\begin{array}{l}\text { Evidence or general agreement is that the treatment or } \\
\text { procedure should not be performed. }\end{array}$ \\
\hline
\end{tabular}

\section{Journal of} Surgery

\author{
Jennifer Chung and Dominique Shum-Tim* \\ Division of Cardiac Surgery, Department of Surgery, McGill \\ University Health Center, McGill University, Montreal, Quebec, \\ Canada
}

\section{*Address for Correspondence}

D. Shum-Tim, M.D.,C.M., MSc., CPSQ., FRCSC., FAHA., FACS., Professor, Department of Surgery, Department of Pediatric Surgery, McGill University Health Center, McGill University, 687 Avenue Des Pins Ouest, Suite S8-73b, Montreal, Quebec, Canada, H3A 1A1, Tel: 514-9341934 x36873; Fax: 514-843-1602; E-mail: dshumtim@yahoo.ca

Copyright: () 2014 Chung J, et al. This is an open access article distributed under the Creative Commons Attribution License, which permits unrestricted use distribution, and reproduction in any medium, provided the original work is properly cited.

Submission: 09 January 2014

Accepted: 27 February 2014

Published: 04 March 2014

Current operative mortality for aortic valve replacement is low at $1-3 \%$ for patients under 70 years old and $4-8 \%$ in older patients [6]. Following surgery, the prognosis improves dramatically. However, survival rate does not return to that expected in the general population. A large Swedish study of 2,359 patients found a relative 15 -year survival rate of $75 \%$ after aortic valve replacement as compared to that expected in the general Swedish population [7]. It is important to remember that aortic valve replacement, although very successful, is not curative; instead it replaces an aortic valve pathology with another far more manageable one.

\section{Aortic regurgitation}

Acute aortic regurgitation is very poorly tolerated and leads to hemodynamic instability, as the unprimed left ventricle has had no time to compensate for the sudden increase in preload. Usually caused by endocarditis or aortic dissection, this entity almost always requires prompt intervention. On the other hand, chronic severe aortic regurgitation is initially well tolerated as the left ventricle gradually adapts with eccentric hypertrophy. Like the natural history of aortic stenosis, there is a latent period during which patients are asymptomatic. Bonow et al. followed 104 patients with asymptomatic chronic severe aortic regurgitation with serial echocardiography [8]. Nearly $60 \%$ of patients remained asymptomatic while retaining normal left ventricular function at 11 years. The annual mortality rate was $0.4 \%$ per year, keeping in mind that 23 patients in the cohort underwent aortic valve replacement mostly due to the onset of symptoms. Analysis of the echocardiographic data identified hingepoints and rise in likelihood of death, development of symptoms and left ventricular dysfunction, occurring at a left ventricular end-systolic dimension (LVESD) of greater than $50 \mathrm{~mm}$, and a left ventricular end-diastolic dimension (LVEDD) of greater than $70 \mathrm{~mm}$.

The understanding of the natural history of aortic regurgitation is the basis of the current AHA guidelines on timing of intervention $[4,5]$. Aortic valve replacement is a Class I recommendation in the setting of symptoms, or in the absence of symptoms with left ventricular dysfunction. In addition, aortic valve replacement is a Class I indication in chronic severe aortic regurgitation in patients undergoing other heart surgery. Furthermore, it is also reasonable to intervene on chronic severe aortic regurgitation if the LVESD is 


\section{Comparison of Outcomes for Mechanical and Bioprosthetic Aortic Valve Replacement}
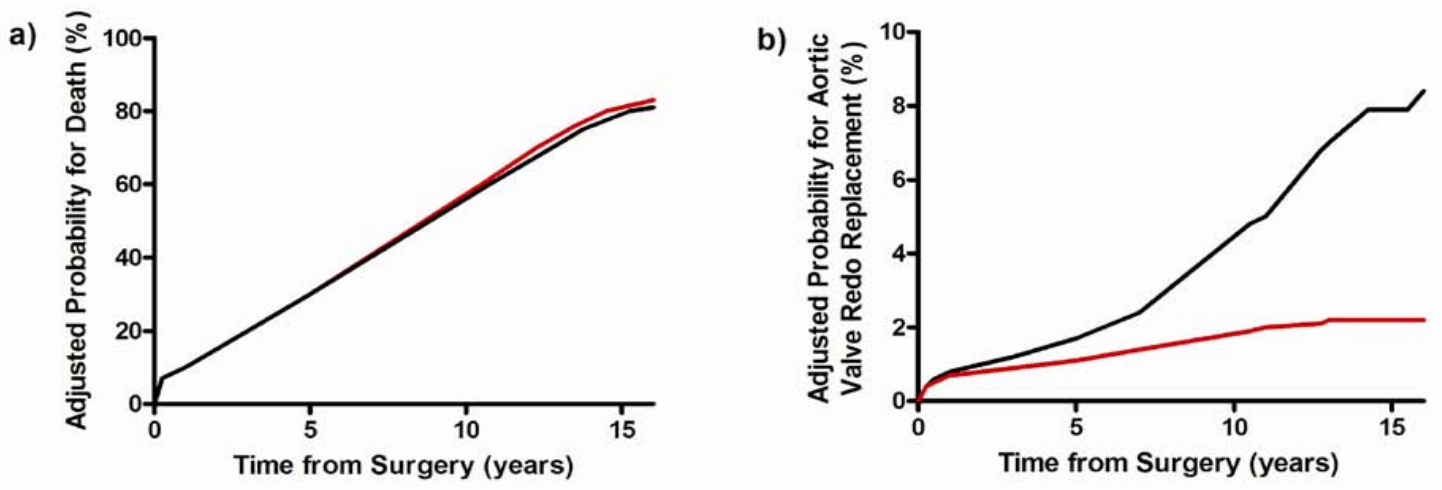

- Mechanical

\section{- Bioprosthetic}

Figure 1: Data from a retrospective review of the STS database. The adjusted mortality is similar between mechanical aortic valves and bioprosthetic aorta valves (a). However the rates of aortic valve replacement re-operation (AVRR) is significantly higher with bioprosthetic valves than with mechanical valves (b). Adapted from Brennan et al. [17].

greater than $50 \mathrm{~mm}$, and one can consider intervention if the LVEDD greater than $65 \mathrm{~mm}$.. The European guidelines use the cut-offs of an LVESD greater than $50 \mathrm{~mm}$, an LVEDD of greater than $70 \mathrm{~mm}$, and an LVESD indexed to body surface area of greater than $25 \mathrm{~mm} / \mathrm{m}^{2}$ [6].

\section{Endocarditis}

Infective endocarditis is a highly variable condition with the clinical presentation ranging from minimally symptomatic to cardiogenic shock. The degree of invasiveness with which the infectious agent penetrates the heart is also highly variable, from a small isolated distinct vegetation to destructive invasion causing complex abscesses and shunts. As such, the treatment options can be either medical or a combination of surgical and medical. In fact, over half of the cases of infective endocarditis can be treated by antibiotics alone [9]. When complications arise, surgery is often indicated.

Complications of native aortic valve endocarditis include valvular dysfunction leading to heart failure and elevated left ventricular end diastolic pressure, breach of structural integrity leading to paravalvular abscesses, heart block and penetrating lesions, and recurrent embolization from vegetations. The above summarizes current Class I and Class IIa indications for surgery [4,5]. Surgery involves drainage of abscesses, debridement of all infected tissue, and reconstruction of the heart and repair of resulting defects. When the process is isolated to the native aortic valve, either mechanical or stented tissue valves are reasonable choices depending on patient characteristics [10]. Homografts may be considered in the setting of annular destruction because of the periannular tissue available. However, compared to stentless root replacements, homografts may experience higher rates of late structural valve degeneration [11].

The timing of surgery is sometimes vexing. Proponents of early surgery suggest that it may reduce the rates of embolization. Embolic events occur in $43 \%$ of cases of native valve endocarditis and $25 \%$ of prosthetic valve endocarditis, and half are in the cerebral territory [12]. Delaying the repair after major stroke may be reasonable, although this is still debated. The only randomized controlled trial on the topic of timing was recently reported by a Korean group [13]. Seventy-six patients with left-sided infective endocarditis, severe valvular disease and a vegetation greater than $10 \mathrm{~mm}$ in size, were randomized to receive early surgery within 48 hours or conventional treatment, where timing of surgery was highly variable. This small trial found significantly higher rates of embolic events at 6 weeks with conventional treatment, and significantly favourable early mortality rates for the early surgery group.

\section{Options for Aortic Valve Intervention}

\section{Mechanical and biological valve replacement}

Once a decision has been made to replace the aortic valve, the next question facing the surgeon and the patient is the selection of the prosthesis most suitable for the patient. Broadly, prostheses may be divided into mechanical or biological aortic valves.

Mechanical aortic valves require lifelong anticoagulation to prevent prosthetic valve thrombosis and thromboembolism. On the other hand, biological valves do not require long-term anticoagulation. Therefore, mechanical valves may not be appropriate for non-compliant patients unable to closely follow INR levels, or high-performance athletes at risk for head injuries. The target range of INR depends on patient as well as valve factors [14]. Patients may have higher risks for thromboembolism based on the presence of atrial fibrillation, depressed ejection fraction, or presence of multiple prosthetic valves. With respect to the valves themselves, some valves are more thrombogenic than others. The original Starr-Edwards caged-ball valves (Baxter Healthcare Corp, Edwards Division, Irvine, Calif), introduced in 1960, usually targets a higher INR range of 3.0 - 4.0. Meanwhile, the newer generation On-X valve (On-X Life Technologies, Austin, TX) is being investigated for an INR range of $1.5-2.0$. For the majority of patients who are not at high risk of thrombosis, an INR of $2.0-3.0$ is recommended along with low-dose aspirin in the AHA guidelines [4]. Low-dose aspirin is to be considered in addition to oral anticoagulation in the ESC 
guidelines [6]. Intravenous unfractionated heparin is recommended at the commencement of anticoagulation and in order to bridge patients requiring procedures. Obligate anticoagulation is obviously problematic during bleeding events. The FDA provides guidance on the expected performance of heart valves, and reports bleeding events of $3.5 \%$ per year for mechanical valves, and $1.4 \%$ per year for biological valves. Grunkemeier et al. extensively reviewed the rates of complications for a variety of valves and found majority of mechanical aortic valves experience fewer than $2 \%$ per year of bleeding events, and most biological aortic valves fewer than $0.5 \%$ per year [15].

The advantage in avoiding anticoagulation with bioprosthetic valves is offset by the increase in rates of structural valve degeneration. This leads to higher rates of reoperation. Traditionally, expected lifespan of the patient is used as a major factor in choosing valve type, with younger patients often being offered the more durable mechanical valve, and older patients being offered bioprosthetic valves. However, the superior durability of newer generation tissue valves have called the age mantra into question [16]. The latest reoperation rates for bioprosthetic valves are only $5.2 \%$ at 12 years ( $2.3 \%$ at 12 years for mechanical valves), which is far lower than rates traditionally quoted to patients [17]. Importantly, this rate is higher for younger patients (up to $10.5 \%$ ), who are more active and expose their valves to greater wear and tear. Limited reports of valve-in-valve technology using transcatheter aortic valve implantation present the real possibility that future biological structural valve degeneration may be treated less invasively $[18,19]$. Likely for the above reasons and also because of the great inconveniences associated with anticoagulation, the current trend in the United States and in Europe is towards the placement of more bioprosthetic valves [16].

Two randomized controlled trials from the early 1990's, as well as a smaller contemporary randomized controlled trial, have shown similar long-term survival with either mechanical or biological prostheses [20-22]. A large retrospective study echoes these findings by showing similar long-term survival with both valve types when adjusted for age [23]. Freedom from thromboembolism is the same for bioprosthetic valves and mechanical valves with anticoagulation at approximately $80-85 \%$ at 10 years [24]. There is no hard evidence that either type of valve is preferable in reducing the risk of prosthetic valve endocarditis. However, the STS database reports that after risk adjustment, the risk for prosthetic valve endocarditis is slightly higher for bioprosthetic valves than with mechanical valves with a hazard ratio of 1.60 (95\% CI, 1.31-1.94) [17]. The overall incidence of prosthetic valve endocarditis was found to be low at $1.9 \%$ with a mean follow-up of 12.6 years.

Generally, it is difficult to compare the two types of valves especially when they are often offered to different patient populations. Specific circumstances pertaining to each individual patient must be considered when making a valve choice, and naturally encouraging the patient to actively participate in the decision-making process is ideal.

\section{Aortic valve repair}

Unlike in mitral valve disease where, in general, repair is preferable to replacement, in aortic valve disease replacement is the mainstay of therapy. Nevertheless, repair is a viable option in select cases with pliable salvageable leaflets. This normally pertains to cases of aortic insufficiency rather than calcific aortic stenosis. The champion of aortic valve repair, Gebrine El Khoury, recently reported his series of 264 consecutive patients, and introduced a classification system for aortic regurgitation based on the Carpentier classification for mitral valve regurgitation [25]. The classification system is as follows: Type I for normal valve motion, Type II for cusp prolapse and Type III for cusp restriction. Based on the classification, one can anticipate different repair strategies. Over half of the patients in the series had concomitant aortic dilatation, majority had tricuspid aortic valves, the cause of the aortic insufficiency was usually degenerative, and there was an isolated valvular lesion in two-thirds of cases. Over $90 \%$ freedom from reoperation was achieved in Type I and Type II aortic insufficiency at 5 years. At ten years, the freedom from valve-related events including reoperation, thromboembolic events, bleeding and endocarditis was 74\% [26]. The Cleveland Clinic group also reported their results with aortic valve repair [27]. They achieved 95, 87 and $84 \%$ freedom from reoperation at 1,5 and 7 years, respectively. Residual aortic insufficiency immediately post repair predicted late aortic regurgitation. Although these results may seem acceptable, these outcomes were achieved in experienced centres, and they are worse than contemporary results for aortic valve replacement. Therefore, at this time, the role of aortic valve repair is still unclear and requires careful patient selection.

\section{Ross procedure}

The Ross procedure was first introduced in 1967 by Donald Ross [28]. The aortic valve is replaced by the patient's own pulmonary valve (pulmonary autograft), and the pulmonary valve is replaced by a homograft or another right ventricular outflow tract conduit. Potential advantages gained by this increased surgical complexity include ability for the autograft to grow with the young patient, no prosthetic material reducing the risks of endocarditis, and freedom from anticoagulation. Magdi Yacoub conducted a trial of 228 patients randomized to either the Ross procedure or a homograft aortic root procedure [29]. The actuarial survival in the Ross group was significantly better, and in fact similar to an age-matched, sexmatched British population. A recent meta-analysis found the rates of both autograft and right ventricular outflow tract conduit deterioration to be less than $1 \%$ per patient-year each [30]. The most important limitations of the Ross procedure are the conversion of a single valve problem into a two valve problem, and the need to upkeep a homograft bank. Other than in the most experienced centres, in the most experienced hands, this technically challenging operation is not typically an option employed by most surgeons to address the aortic valve in the adult patient population.

\section{Balloon valvotomy}

Balloon valvotomy is the use of a transcatheter balloon across the stenotic aortic valve in an attempt to enlarge the orifice area. Unfortunately this technique is limited in efficacy. Rarely does the post-valvotomy valve area exceed $1.0 \mathrm{~cm}^{2}$, and restenosis occurs quickly and frequently [31]. Moreover, up to a quarter of patients experience serious complications within 24 hours [32]. Results with balloon valvotomy are poor with $93 \%$ of patients dying or undergoing aortic valve replacement in a 6 year period, suggesting similar outcomes to the natural history of untreated severe aortic stenosis [33]. Needless to say, there are currently no Class I or Class 
IIa indications for this procedure, but still it may be considered as a bridge to surgery for hemodynamically unstable patients [4]. The role for balloon valvotomy as a palliative treatment for extremely high risk patients is unclear in the era of transcatheter aortic valve implantation (TAVI, next section). Given the development of rapid ventricular pacing and the Inoue balloon since the earlier studies [34], one can argue that balloon valvotomy may still play a role in high risk patients not anatomically suitable for TAVI. One caveat is that both surgical and transcatheter balloon valvotomy are still routinely used in congenital heart surgery to treat critical aortic stenosis chosen for biventricular repair, given the size and need for growth in the congenital population [35].

\section{Transcatheter aortic valve implantation}

Despite the success of aortic valve replacement (AVR), one third of patients with severe symptomatic aortic stenosis do not undergo heart surgery because of perceived high operative risk, especially secondary to age, reduced ejection fraction and neurological dysfunction [36]. Other considerations for not undergoing surgery include patient preference, terminal illness, porcelain aortas or complex redo surgery. A significant number of patients would therefore benefit from a less invasive procedure intervening on the aortic valve.

On the shoulders of technology for balloon valvotomy, researchers have been studying catheter mounted valves since the early 1990's The concept behind transcatheter aortic valve implantation (TAVI) is to deliver a valve through peripheral access and then seat the valve not with sutures but by the radial force of a stent instead.

There are currently two main devices on the market: the Sapien Valve (Edwards Life Sciences, Inc., Irvine, CA) and the CoreValve (Medtronic, Inc., Minneapolis, MN) [37]. The Sapien valve is a balloon expandable bovine pericardial valve mounted in a cobalt chromium alloy stent. It is available in $23 \mathrm{~mm}, 26 \mathrm{~mm}$ and $29 \mathrm{~mm}$ sizes and is delivered in a $18 \mathrm{Fr}$ sheath. The CoreValve is a porcine pericardial valve mounted in a self-expanding nitonol sheath. It is available in $26 \mathrm{~mm}, 29 \mathrm{~mm}$ and $31 \mathrm{~mm}$ sizes and is also deliverable in a $18 \mathrm{Fr}$ sheath. Recently, a head-to-head comparison of these two valves was conducted in a study of databases from four experienced European centres, using propensity risk-score matching resulting in 204 patients in each group [38]. The study found that virtually the same outcome was achieved using either valve, and that the complication rates were similar as well except for permanent pacemaker implantation which was seen more frequently in the CoreValve group. Of note, newer devices have been developed and are entering the market, such as the Portico valve (St. Jude Medical, Minneapolis, Minnesota), the first transcatheter valve that can be completely resheathed and repositioned [39].

The trial that ushered TAVI into the mainstream is the Partner trial. This Edwards sponsored multicentre randomized controlled trial was divided into two cohorts. The Cohort B arm studied patients with severe symptomatic aortic stenosis that two surgeons had decided were not candidates for surgery [40]. A total of 358 patients were recruited for this superiority trial, representing $12 \%$ of the patients screened. The patients were randomized to receive either TAVI or standard therapy which included a number of treatment options such as balloon valvotomy or medical management. Despite being "nonsurgical candidates", $6.7 \%$ of these patients eventually underwent surgery. A highly significant and striking finding of decreased 1-year mortality of $30 \%$ from $50 \%$ in the TAVI group as compared to the standard therapy group consolidated TAVI as a key therapy option for this population.

The Cohort A arm was made up of patients with elevated but not prohibitive surgical risk (the average STS score was 11.8\%) [41]. A total of 699 patients were recruited for this non-inferiority study, and randomized to receive either TAVI or surgical aortic valve replacement (AVR). The primary endpoint, one year mortality rate, was $24.2 \%$ in the TAVI group as compared to $26.8 \%$ in the AVR group, and these rates were not statistically different. Naturally there were higher rates of vascular complications in the TAVI group and higher rates of bleeding in the surgical group. A signal for increased stroke in the TAVI group was uncovered $(p=0.07)$, which then disappeared by the 2-year follow up [42]. The most important finding from the 2-year follow up was the disturbingly high and ongoing rate of aortic regurgitation which did not show signs of slowing with time from implantation. An association with increased rate of death even with mild aortic regurgitation was shown.

Thus, while an important asset in the treatment of aortic stenosis for patients with prohibitively high risk for surgery, TAVI is still finding its role among patients who are candidates for surgery. Should younger patients who would otherwise tolerate an invasive surgical AVR be exposed to this ongoing rate of aortic regurgitation, especially when it is associated with increased mortality? In addition, it is important to note that TAVI cannot be offered to everyone. Careful pre-operative work-up is mandatory to ensure anatomical appropriateness for the procedure. This evaluation includes accurate aortic annulus and root sizing, positioning of coronary arteries, delineation of iliofemoral anatomy and other potential vascular accesses [43]. Especially given that nearly all of the evidence supporting TAVI is derived from a single randomized controlled trial with limited follow-up, the great enthusiasm for this technique, which does hold great promise, is tempered by its limitations.

\section{Sutureless aortic valves}

Transcatheter aortic valve implantation revealed the unmet need in treating patients with severe aortic stenosis who do not undergo conventional aortic valve replacement (AVR). However, It was shown that most individuals with severe symptomatic aortic stenosis who do not undergo AVR were not referred to a surgeon for proper risk assessment and when risks were calculated objectively, oftentimes the risks of surgery were not excessively elevated [44]. There was therefore great interest in reducing the invasiveness of open surgery in order to meet the needs of this population of patients who would benefit from open surgery and yet for whom surgery was denied. The sutureless aortic valve replacement (SAVR) was developed to fill this niche.

SAVR requires cardiopulmonary bypass and removal and decalcifcation of the native diseased valve. Valves are mounted on stents and deployed under direct vision onto the aortic annulus. By requiring minimal suturing, the cross-clamp and cardiopulmonary bypass times can be minimized. In turn, this theoretically reduces the morbidity associated with long surgeries involving multiple procedures such as bypasses in high-risk patients. SAVR also plays a potentially powerful role in minimal access surgery. The main strength of this technique is that it addresses shortfallings of TAVI, 
specifically stroke and paravalvular leak, which are hypothesized to be related to the lack of valve decalcification done in conventional surgery. Early data from a small propensity-score matched study comparing TAVI to SAVR suggests that SAVR may deliver similar results with fewer incidences of paravalvular leak [45].

There are currently three SAVR valves available: The $3 \mathrm{f}$ Enable (ATS Medical Inc., Minneapolis, MN, USA), the Intuity (Edwards Lifesciences LLC, Irvine, Calif), and the Perceval S (Sorin Biomedica Cardio, Saluggia, Italy). The Enable is based on the $3 \mathrm{f}$ valve, an equine pericardial valve mounted on a self-expanding temperature sensitive nitinol frame, and is delivered with a single guiding suture. Initial studies confirm the valve's feasibility and safety $[46,47]$. The Intuity valve is a stented bovine pericardial bioprosthesis with a skirt that sits below the annulus as an anchor. The valve is expanded via balloon inflation after being guided into position by three sutures. The 1-year single-arm results have been reported and demonstrate safety as well [48]. The third valve, the Perceval S, a bovine pericardial valve on a self-expanding stent is truly sutureless and also has promising safety data [49]. No large randomized controlled trial has yet been reported with SAVR. Therefore, this technology is still striving to find its applicability amongst the continuum of patients who require intervention on the aortic valve.

\section{Future Directions}

\section{Tissue engineered aortic valves}

The ideal valve replacement would be without prosthetic materials, and able to respond to growth and physiological forces. Scientists are attempting to achieve this through tissue engineering, and this would be a major breakthrough especially for the congenital heart disease population. The two approaches used are regeneration and repopulation and are outlined elsewhere [50]. Valve tissue engineering is particularly challenging due to 40 million opening and closings per year of the average heart valve, necessitating design of a durable and pliable extracellular matrix able to respond to injury [51]. A number of scaffold sources and cell sources have been explored and early in vivo studies have been encouraging [52].

\section{Conclusions}

Aortic valve disease is structural in nature, the endpoint of which often requires surgery for structural correction. Timing of intervention greatly depends on the understanding of the natural history of the aortic valve condition. Presently, many options exist for intervention on the aortic valve from traditional aortic valve replacement to cutting edge transcatheter aortic valve implantation and sutureless aortic valves, and possibly even tissue engineered valves in the future.

\section{References}

1. Kurtz CE, Otto CM (2010) Aortic stenosis: clinical aspects of diagnosis and management, with 10 illustrative case reports from a 25-year experience. Medicine (Baltimore) 89: 349-379.

2. Horstkotte $D$, Loogen $F(1988)$ The natural history of aortic valve stenosis. Eur Heart J 9: 57-64.

3. Pellikka PA, Sarano ME, Nishimura RA, Malouf JF, Bailey KR, et al. (2005) Outcome of 622 adults with asymptomatic, hemodynamically significant aortic stenosis during prolonged follow-up. Circulation 111: 3290-3295.

4. American College of Cardiology/American Heart Association Task Force on Practice; Society of Cardiovascular Anesthesiologists; Society for Cardiovascular Angiography and Interventions; Society of Thoracic Surgeons, Bonow RO, et al. (2006) ACC/AHA 2006 guidelines for the management of patients with valvular heart disease: a report of the American College of Cardiology/American Heart Association Task Force on Practice Guidelines (writing committee to revise the 1998 Guidelines for the Management of Patients With Valvular Heart Disease): developed in collaboration with the Society of Cardiovascular Anesthesiologists: endorsed by the Society for Cardiovascular Angiography and Interventions and the Society of Thoracic Surgeons. Circulation 114: e84-e231.

5. Nishimura RA, Otto CM, Bonow RO, Carabello BA, Erwin JP 3rd, et al. (2014) 2014 AHA/ACC guideline for the management of patients with valvular heart disease: A report of the American College of Cardiology/American Heart Association Task Force on practice guidelines. J Am Coll Cardiol [Epub ahead of print].

6. Joint Task Force on the Management of Valvular Heart Disease of the European Society of Cardiology (ESC); European Association for CardioThoracic Surgery (EACTS), Vahanian A, Alfieri O, Andreotti F, et al. (2012) Guidelines on the management of valvular heart disease (version 2012). Eur Heart J 33: 2451-2496.

7. Kvidal P, Bergstrom R, Horte LG, Stahle E (2000) Observed and relative survival after aortic valve replacement. J Am Coll Cardiol 35: 747-756.

8. Bonow RO, Lakatos E, Maron BJ, Epstein SE (1991) Serial long-term assessment of the natural history of asymptomatic patients with chronic aortic regurgitation and normal left ventricular systolic function. Circulation 84: $1625-1635$

9. Baddour LM, Wilson WR, Bayer AS, Fowler VG Jr, Bolger AF, et al. (2005) Infective endocarditis: diagnosis, antimicrobial therapy, and management of complications: a statement for healthcare professionals from the Committee on Rheumatic Fever, Endocarditis, and Kawasaki Disease, Council on Cardiovascular Disease in the Young, and the Councils on Clinical Cardiology, Stroke, and Cardiovascular Surgery and Anesthesia, American Heart Association: endorsed by the Infectious Diseases Society of America. Circulation 111: e394-e434.

10. Byrne JG, Rezai K, Sanchez JA, Bernstein RA, Okum E, et al. (2011) Surgical management of endocarditis: the society of thoracic surgeons clinical practice guideline. Ann Thorac Surg 91: 2012-2019

11. El-Hamamsy I, Clark L, Stevens LM, Sarang Z, Melina G, et al. (2010) Late outcomes following freestyle versus homograft aortic root replacement: results from a prospective randomized trial. J Am Coll Cardiol 55: 368-376.

12. Sandre RM, Shafran SD (1996) Infective endocarditis: review of 135 cases over 9 years. Clin Infect Dis 22: 276-286.

13. Kang DH, Kim YJ, Kim SH, Sun BJ, Kim DH, et al. (2012) Early surgery versus conventional treatment for infective endocarditis. N Engl J Med 366: 2466-2473.

14. Butchart EG, Gohlke-Barwolf C, Antunes MJ, Tornos P, De Caterina R, et al. (2005) Recommendations for the management of patients after heart valve surgery. Eur Heart J 26: 2463-2471.

15. Grunkemeier GL, Li HH, Naftel DC, Starr A, Rahimtoola SH (2000) Long-term performance of heart valve prostheses. Curr Probl Cardiol 25: 73-154.

16. El Oakley R, Kleine P, Bach DS (2008) Choice of prosthetic heart valve in today's practice. Circulation 117: 253-256.

17. Brennan JM, Edwards FH, Zhao Y, O'Brien S, Booth ME, et al. (2013) Longterm safety and effectiveness of mechanical versus biologic aortic valve prostheses in older patients: results from the Society of Thoracic Surgeons Adult Cardiac Surgery National Database. Circulation 127: 1647-1655.

18. Webb JG, Wood DA, Ye J, Gurvitch R, Masson JB, et al. (2010) Transcatheter valve-in-valve implantation for failed bioprosthetic heart valves. Circulation 121: $1848-1857$

19. Eggebrecht H, Schäfer U, Treede H, Boekstegers P, Babin-Ebell J, et al. 
(2011) Valve-in-valve transcatheter aortic valve implantation for degenerated bioprosthetic heart valves. JACC Cardiovasc Interv 4: 1218-1227.

20. Bloomfield P, Wheatley DJ, Prescott RJ, Miller HC (1991) Twelveyear comparison of a Bjork-Shiley mechanical heart valve with porcine bioprostheses. N Engl J Med 324: 573-579.

21. Hammermeister KE, Sethi GK, Henderson WG, Oprian C, Kim T, et al. (1993) A comparison of outcomes in men 11 years after heart-valve replacement with a mechanical valve or bioprosthesis. Veterans Affairs Cooperative Study on Valvular Heart Disease. N Engl J Med 328: 1289-1296.

22. Stassano P, Di Tommaso L, Monaco M, Iorio F, Pepino P, et al. (2009) Aortic valve replacement: a prospective randomized evaluation of mechanical versus biological valves in patients ages 55 to 70 years. J Am Coll Cardiol 54 1862-1868.

23. Grunkemeier GL, Li HH, Starr A (1999) Heart valve replacement: a statistical review of 35 years' results. J Heart Valve Dis 8: 466-470.

24. Khan SS, Trento A, DeRobertis M, Kass RM, Sandhu M, et al. (2001) Twenty year comparison of tissue and mechanical valve replacement. J Thorac Cardiovasc Surg 122: 257-269.

25. Boodhwani M, de Kerchove L, Glineur D, Poncelet A, Rubay J, et al. (2009) Repair-oriented classification of aortic insufficiency: impact on surgical techniques and clinical outcomes. J Thorac Cardiovasc Surg 137: 286-294.

26. Price J, De Kerchove L, Glineur D, Vanoverschelde JL, Noirhomme P, et al. (2013) Risk of valve-related events after aortic valve repair. Ann Thorac Surg 95: 606-612.

27. Casselman FP, Gillinov AM, Akhrass R, Kasirajan V, Blackstone EH, et al. (1999) Intermediate-term durability of bicuspid aortic valve repair for prolapsing leaflet. Eur J Cardiothorac Surg 15: 302-308.

28. Ross DN (1967) Replacement of aortic and mitral valves with a pulmonary autograft. Lancet 4: 956-958.

29. El-Hamamsy I, Eryigit Z, Stevens LM, Sarang Z, George R, et al. (2010) Long-term outcomes after autograft versus homograft aortic root replacement in adults with aortic valve disease: a randomised controlled trial. Lancet 376 : 524-531.

30. Takkenberg JJ, Klieverik LM, Schoof PH, van Suylen RJ, van Herwerden LA et al. (2009) The Ross procedure: a systematic review and meta-analysis. Circulation 119: 222-228.

31. Otto CM, Mickel MC, Kennedy JW, Alderman EL, Bashore TM, et al. (1994) Three-year outcome after balloon aortic valvuloplasty. Insights into prognosis of valvular aortic stenosis. Circulation 89: 642-650.

32. Berland J, Cribier A, Savin T, Lefebvre E, Koning R, et al. (1989) Percutaneous balloon valvuloplasty in patients with severe aortic stenosis and low ejection fraction. Immediate results and 1-year follow-up. Circulation 79: 1189-1196.

33. Lieberman EB, Bashore TM, Hermiller JB, Wilson JS, Pieper KS, et al. (1995) Balloon aortic valvuloplasty in adults: failure of procedure to improve longterm survival. J Am Coll Cardiol 26: 1522-1528.

34. Hara H, Pedersen WR, Ladich E, Mooney M, Virmani R, et al. (2007) Percutaneous balloon aortic valvuloplasty revisited: time for a renaissance? Circulation 115: e334-e338

35. McCrindle BW, Blackstone EH, Williams WG, Sittiwangkul R, Spray TL, et al. (2001) Are outcomes of surgical versus transcatheter balloon valvotomy equivalent in neonatal critical aortic stenosis? Circulation 104: I152-I158

36. Iung B, Cachier A, Baron G, Messika-Zeitoun D, Delahaye F, et al. (2005) Decision-making in elderly patients with severe aortic stenosis: why are so many denied surgery? Eur Heart J 26: 2714-2720.
37. Holmes DR Jr, Mack MJ, Kaul S, Agnihotri A, Alexander KP, et al. (2012) 2012 ACCF/AATS/SCAI/STS expert consensus document on transcatheter aortic valve replacement. J Am Coll Cardiol 59: 1200-1254

38. Chieffo A, Buchanan GL, Van Mieghem NM, Tchetche D, Dumonteil N, et al. (2013) Transcatheter aortic valve implantation with the Edwards SAPIEN versus the Medtronic CoreValve Revalving system devices: a multicenter collaborative study: the PRAGMATIC Plus Initiative (Pooled-RotterdAmMilano-Toulouse In Collaboration). J Am Coll Cardiol 61: 830-836.

39. Willson AB, Rodès-Cabau J, Wood DA, Leipsic J, Cheung A, et al. (2012) Transcatheter aortic valve replacement with the St. Jude Medical Portico valve: first-in-human experience. J Am Coll Cardiol 60: 581-586.

40. Leon MB, Smith CR, Mack M, Miller DC, Moses JW, et al. (2010) Transcatheter aortic-valve implantation for aortic stenosis in patients who cannot undergo surgery. N Engl J Med 363: 1597-1607.

41. Smith CR, Leon MB, Mack MJ, Miller DC, Moses JW, et al. (2011) Transcatheter versus surgical aortic-valve replacement in high-risk patients. N Engl J Med 364: 2187-2198.

42. Kodali SK, Williams MR, Smith CR, Svensson LG, Webb JG, et al. (2012) Two-year outcomes after transcatheter or surgical aortic-valve replacement. N Engl J Med 366: 1686-1695.

43. Leipsic J, Gurvitch R, Labounty TM, Min JK, Wood D, et al. (2011) Multidetector computed tomography in transcatheter aortic valve implantation. JACC Cardiovasc Imaging 4: 416-429.

44. Bach DS, Siao D, Girard SE, Duvernoy C, McCallister BD Jr, et al. (2009) Evaluation of patients with severe symptomatic aortic stenosis who do not undergo aortic valve replacement: the potential role of subjectively overestimated operative risk. Circ Cardiovasc Qual Outcomes 2: 533-539.

45. D'Onofrio A, Messina A, Lorusso R, Alfieri OR, Fusari M, et al. (2012) Sutureless aortic valve replacement as an alternative treatment for patients belonging to the "gray zone" between transcatheter aortic valve implantation and conventional surgery: a propensity-matched, multicenter analysis. J Thorac Cardiovasc Surg 144: 1010-1016.

46. Wendt D, Thielmann M, Buck T, Jánosi RA, Bossert T, et al. (2008) First clinical experience and 1-year follow-up with the sutureless 3F-Enable aortic valve prosthesis. Eur J Cardiothorac Surg 33: 542-547.

47. Martens S, Sadowski J, Eckstein FS, Bartus K, Kapelak B, et al. (2011) Clinical experience with the ATS $3 f$ Enable ${ }^{\circledR}$ Sutureless Bioprosthesis. Eur J Cardiothorac Surg 40: 749-755

48. Kocher AA, Laufer G, Haverich A, Shrestha M, Walther T, et al (2013) Oneyear outcomes of the Surgical Treatment of Aortic Stenosis With a Next Generation Surgical Aortic Valve (TRITON) trial: a prospective multicenter study of rapid-deployment aortic valve replacement with the EDWARDS INTUITY Valve System. J Thorac Cardiovasc Surg 145: 110-115.

49. Folliguet TA, Laborde F, Zannis K, Ghorayeb G, Haverich A, et al. (2012) Sutureless perceval aortic valve replacement: results of two European centers. Ann Thorac Surg 93: 1483-1488.

50. Vesely I (2005) Heart valve tissue engineering. Circ Res 97: 743-755.

51. Sacks MS, Schoen FJ, Mayer JE (2009) Bioengineering challenges for heart valve tissue engineering. Annu Rev Biomed Eng 11: 289-313.

52. Apte SS, Paul A, Prakash S, Shum-Tim D (2011) Current developments in the tissue engineering of autologous heart valves: moving towards clinical use. Future Cardiol 7: 77-97. 